\title{
Reversing the Marginalization of Global Environmental Politics in International Relations: An Opportunity for the Discipline
}

Jessica F. Green, New York University

Thomas N. Hale, Oxford University

ABSTRACT Despite the increasing urgency of many environmental problems, environmental politics remains at the margins of the discipline. Using data from the Teaching, Research, and International Policy (TRIP) project, this article identifies a puzzle: the majority of international relations (IR) scholars find climate change among the top three most important policy issues today, yet fewer than $4 \%$ identify the environment as their primary area of research. Moreover, environmental research is rarely published in top IR journals, although there has been a recent surge in work focused on climate change. The authors argue that greater attention to environmental issues-including those beyond climate change-in IR can bring significant benefits to the discipline, and they discuss three lines of research to correct this imbalance.

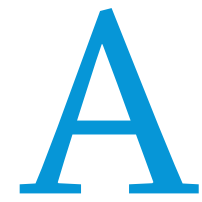
s environmental problems grow more globalized, severe, and salient, it is increasingly clear that the effectiveness of cross-border environmental governance in the twenty-first century will have stark implications for interstate conflict, civil violence, and human welfare more broadly. With strong links among security, health, and development, on the one hand, and deforestation, availability of clean water, biodiversity and species loss, and climate change on the other, quality of life increasingly depends on our ability to manage global environmental challenges. As a consequence, global environmental policy making and political contestation have increased markedly in recent decades. Countries have created hundreds of multilateral environmental agreements (Mitchell 2016) and intergovernmental organizations, billions of dollars of "green aid" have crossed borders (Hicks et al. 2008), and scores of transnational networks and governance initiatives have emerged (Bulkeley et al. 2014).

The reality of politics in the "Anthropocene" has not been lost on international relations (IR) scholars. In a February 2016 "snap poll” administered by the Teaching, Research, and International

Jessica F. Green is assistant professor of environmental studies at New York University. She can be reached at jessica.green@nyu.edu.

Thomas N. Hale is associate professor of public policy at the Blavatnik School of Government, Oxford University. He can be reached at thomas.hale@bsg.ox.ac.uk.
Policy (TRIP) project, $51 \%$ of all US-based IR scholars surveyed ranked global climate change among the top three most important policy issues facing the United States today. The only other comparable issue is the conflict in the Middle East, which $52 \%$ of scholars identified among the top three. ${ }^{1}$ Moreover, $46 \%$ are of the view that climate change will remain at the forefront of foreign policy throughout the next decade. ${ }^{2}$

It is puzzling, then, how little work our discipline has invested in understanding and explaining global environmental politics (GEP). This article presents new data from the TRIP project that show systematic underrepresentation of global environmental issues in the topics that scholars choose to study and among articles that leading disciplinary journals choose to publish.

Political scientists, of course, have long recognized environmental issues as a subject of world politics (Haas, Keohane, and Levy 1993) and have made significant contributions to the study of environmental challenges. An active subfield publishes in journals including Global Environmental Politics and is organized via institutions such as the Environmental Studies Section of the International Studies Association. Political scientists also contribute to more multidisciplinary thematic journals including Climatic Change and Global Environmental Change, and they have an active role in thematic projects such as the Earth Systems Governance Project. However, as a field, we have "punched well below our weight" in public discourse despite the fundamentally political 
nature of environmental challenges. For example, economists dominate discussions about the construction of carbon markets (Aldy and Stavins 2012; Keohane, Petsonk, and Hanafi 2015). Geographers and ecologists are particularly active in research related to deforestation (Phelps, Webb, and Agrawal 2010). Legal scholars write far more on international environmental regimes than political scientists (Bodansky 2010; Sands and Peel 2012). Recent interventions by Javeline (2014) and Keohane (2015) that decry a lack of political scientific attention to even a relatively salient topic such as climate change underscore this gap.

Echoing and expanding on these calls for more contributions by political scientists, we argue for a redoubling of IR research on environmental issues. We document the troubling deficit of IR scholarship on the environment and then discuss three lines of research to correct this imbalance.

Increased engagement will have three distinct but linked benefits. First, it is normatively important for the field to apply social-scientific analysis to the issues that a majority of scholars in the discipline-and the wider world-think matter. Just as the field has focused attention on critical issues as they arise in world politics (e.g., nuclear deterrence, economic globalization, and civil conflicts), the emergence of the Anthropocene also requires us to the environment. Second, the environment is woefully underrepresented in major IR journals. Third, the recent surge in environment-related research is focused almost exclusively on climate change.

\section{A Dearth of Environmental Scholars and Scholarship}

Using the 2014 TRIP faculty survey data, we found that only 3.2\% of IR scholars identify the environment as their primary area of research. 5 In contrast, $12 \%$ list international political economy as their chief area of focus and $20 \%$ devote themselves primarily to international security. Even if we include scholars who identify the environment as a secondary research interest (i.e., 3.8\%), the total is only about $7 \%$ of US IR scholars who can be classified as either primary or secondary GEP scholars. ${ }^{6}$ We consider this percentage to be strikingly small, given the number and magnitude of environmental challenges we face and the stated concerns of scholars themselves.

Worse, not only are GEP scholars a small minority, their work also is underrepresented in top journals. The TRIP database includes 5,306 journal articles in 12 leading IR journals (as defined by impact factor when the database was created) from 1980 to 2012, which the survey organizers defined as field-leading.7

\section{Just as the field has focused attention on critical issues as they arise in world politics (e.g., nuclear deterrence, economic globalization, and civil conflicts), the emergence of the Anthropocene also requires us to study the politics of the environment.}

study the politics of the environment. Second, as in all subfields, environmental politics will benefit from increased engagement with the wider discipline. Third, we contend that bringing environmental politics into the IR mainstream will yield substantial theoretical benefits for the discipline by expanding our range of empirical subjects and applying social-scientific techniques to distinct political dynamics.

\section{EMPIRICAL FINDINGS: THE MARGINALIZATION OF ENVIRONMENT WITHIN IR}

Senior IR scholars have recently lamented in prominent disciplinary publications the field's "slow response" to climate change (Keohane 2015,19$)$ to show how political scientists have been "largely absent" from enormous fields of environmental concern, such as climate adaptation (Javeline 2014, 421) and to call for further research on the politics of the environment (Cao et al. 2013). This article provides new quantitative evidence to demonstrate that this neglect in some ways is worse than these authors suggest, although it is actually less true of climate change than of other environmental topics.

Following Mitchell, we understand environmental scholarship as research that examines activities that "manage or prevent human impacts on natural resources; plant and animal species (including in agriculture, since agriculture modifies both); the atmosphere; oceans; rivers; lakes; terrestrial habitats; and other elements of the natural world that provide ecosystem services."3 As part of a larger TRIP project, we analyzed both the number of IR scholars studying GEP and the patterns of publication in top IR journals, as defined by the TRIP project. 4 The main findings are three. First, only a small number of IR scholars report studying
The database codes both the "issue area" under which an article is categorized (i.e., which IR subfield) and the substantive focus of the article. Only 65 articles (1.23\%) fell into the environment issue area and only 124 (2.34\%) had a substantive focus on environmental issues. ${ }^{8}$ Given that GEP scholars represent $7 \%$ of the discipline, it seems reasonable to infer that they are underrepresented in top journals, although the comparison is inexact. To be sure, other excellent IR journals publish more environmentally oriented research, including Global Environmental Politics and Environmental Politics. However, this is precisely our point: IR scholars who want to contribute to scholarly discussions on environmental issues generally do so in journals that are read principally by other specialists, not in the journals that lead the field as a whole. Moreover, this underrepresentation can become self-sustaining because scholars seeking to place an environmental article in a good journal may have a greater incentive to publish in an environmentally focused outlet rather than a disciplinary publication.

Without doubt, there are other underrepresented issues in IR. Only $2.68 \%$ of articles were categorized in the human-rights issue area; the related topics of migration and humanitarian intervention comprised $1.34 \%$ and $2.38 \%$, respectively. Thus, environment is among the most neglected issues in IR but certainly not the only one. However, political scientists do not rate as highly as the environment any of these other underrepresented issues in polls that ask which issues dominate world politics. In other words, the vast gap between perceived importance and actual work is unique to the environmental issue.

The marginality of environmental politics in IR is mirrored in comparative politics, in which a recent volume identifies a "mutual 
disengagement" between the comparative study of national politics and the study of environmental politics (Steinberg and VanDeveer 2012, 372). A survey of two leading comparativepolitics journals between 1990 and 2010 found only nine articles (approximately 1\%) that refer to the environment (ibid. 373.).9 We conjecture that this trend extends beyond the subfields of IR and comparative politics.

\section{This Just In: Climate Change!}

This disconnect is troubling and puzzling: Why are IR scholars not studying problems that they recognize to be among the most important in world politics? A partial answer appears be a simple lag between policy salience and scholarship. Research agendas are "sticky" and academic research and publication-especially the high-quality social science most valued by the field-takes time.
A similar trend appears from articles published in the TRIP database (table 2). GEP articles are as likely as non-GEP articles to include policy analysis and policy prescriptions or to engage in paradigmatic studies. The only dimension on which they differ is a greater focus on contemporary issues, which is not surprising given the relatively recent (e.g., post-1970s) rise of GEP. We did not observe the articles (GEP-focused or otherwise) that are not published in top journals, so we cannot state whether the proportion of GEP as a whole is similar or dissimilar to the top journals and how this compares to other subfields. Nevertheless, based only on the work available, it seems unlikely that the nature of the scholarship or a policy orientation of the scholars explains the observed gap.

The evidence indicates two structural factors that may explain the underrepresentation of environmental politics in IR. First, GEP

\section{In other words, the vast gap between perceived importance and actual work is unique to the environmental issue.}

Indeed, the data show an increasing representation of global environmental issues in IR as research agendas shift and, in particular, as climate change has come to the forefront in discussions of world politics. Furthermore, a number of recent monographs on climate change are not captured by the dataset (Bulkeley et al. 2014; Green 2014; Hadden 2015).

Fully $24 \%$ of all articles on the environment in the TRIP database were published in the last two years of the 22-year datasetbetween 2010 and 2012. Of these 30 articles, $60 \%$ focused on climate change. The others addressed a variety of issues including river management, pollution, water, and more general issues concerning international negotiations and governance. The data show that, as a discipline, we are only recently becoming aware of environmental issues; nevertheless, the research agenda is largely dominated by climate change.

Interestingly, it appears that Europeans are leading the way in this new wave of environmental research. Since 2014, almost a third of environmental research was published in European outlets: European Journal of International Relations and British Journal of Political Science. Relatedly, the majority of authors of these works are based at European universities; only $37 \%$ of the first authors are from American institutions.

\section{What Explains the Lack of Attention to the Environment in IR?}

An in-depth examination of scholars' choices about their research agendas is beyond the scope of this brief commentary. However, it is useful to draw on the available data to suggest possible explanations and eliminate others. Evidence from the TRIP database shows that environmental scholars, for the most part, are representative of IR scholars as a whole (table 1). In general, they do not appear to be more activist-oriented than other IR scholars, with no significant difference in citing current events or public appeal as a research motivation. They also generally have the same ideas about the ways in which IR scholars should contribute to policy making. Although it seems that GEP scholars are less likely to cite a methodological or paradigmatic orientation as their chief research motivation, these differences are small in magnitude. scholars are more likely to be female than in other parts of IR: $34 \%$ of GEP scholars are women; the equivalent statistic for other parts of IR is $26 \%$. This difference, although not enormous, is statistically significant $(\mathrm{p}<0.1)$. Given that women publish less than men in the top IR journals-comprising only $15.6 \%$ of first authors and $19.5 \%$ of authors overall-it is reasonable to infer that the larger proportion of women in GEP could explain lower rates of environment-related publications. From these data, we cannot state whether it is bias against women that restricts GEP or bias

Table 1

Characteristics and Views of GEP and non-GEP Scholars

\begin{tabular}{|c|c|c|c|}
\hline & GEP & Non-GEP & Significance \\
\hline \multicolumn{4}{|l|}{ Gender } \\
\hline Female & $34 \%$ & $26 \%$ & * \\
\hline Male & $66 \%$ & $74 \%$ & * \\
\hline Sample size & 127 & 1420 & \\
\hline \multicolumn{4}{|l|}{ Research motivations } \\
\hline Appeal to popular audience & $2 \%$ & $3 \%$ & \\
\hline Issue area & $45 \%$ & $39 \%$ & * \\
\hline Methodology & $0 \%$ & $3 \%$ & $* * *$ \\
\hline Paradigm & $3 \%$ & $5 \%$ & ** \\
\hline Policy relevance / current events & $36 \%$ & $34 \%$ & \\
\hline Sample size & 207 & 2555 & \\
\hline \multicolumn{4}{|c|}{ Ideal relationship between academic and policy communities } \\
\hline $\begin{array}{l}\text { There should be a higher wall } \\
\text { of separation }\end{array}$ & $7 \%$ & $11 \%$ & * \\
\hline $\begin{array}{l}\text { There should be a larger } \\
\text { number of links }\end{array}$ & $93 \%$ & $89 \%$ & * \\
\hline Sample size & 145 & 1894 & \\
\hline
\end{tabular}


Table 2

Comparison of Environmental and

Non-Environmental Articles in Top IR

Journals 1980-2012

\begin{tabular}{lrrrr}
\multicolumn{2}{c}{ Non-enviro articles } & \multicolumn{2}{c}{ Enviro articles } \\
\hline & N & $\%$ & N & $\%$ \\
\hline Policy Analysis & & & & \\
\hline No & 4,935 & $95.3 \%$ & 122 & $97.6 \%$ \\
\hline Yes & 246 & $4.7 \%$ & 3 & $2.4 \%$ \\
\hline Policy Prescription & & & & \\
\hline No & 4,688 & $90.5 \%$ & 117 & $93.6 \%$ \\
\hline Yes & 493 & $9.5 \%$ & 8 & $6.4 \%$ \\
\hline Contemporary*** & & & & \\
\hline No & 962 & $23.1 \%$ & 11 & $10.1 \%$ \\
\hline Yes & 3199 & $76.9 \%$ & 98 & $89.9 \%$ \\
\hline Non-paradigmatic & & & & \\
\hline No & 1851 & $35.7 \%$ & 45 & $36.0 \%$ \\
\hline Yes & 3330 & $64.3 \%$ & 80 & $64.0 \%$ \\
\hline
\end{tabular}

Note: Statistical differences were assessed using chi-square tests

***p-value $<0.01 ;{ }^{* *} \mathrm{p}$-value $<0.05 ;{ }^{*} \mathrm{p}$-value.

Contemporary question was deemed not applicable for 1,036 articles. (Source: TRIP)

against GEP that restricts women, but the two dynamics very well may reinforce one another.

Second, environmental politics generally is not taught to graduate students. A recent study of IR field seminar syllabi in 42 universities revealed that not a single article from the flagship journal Global Environmental Politics was assigned (Colgan 2016). Indeed, the author estimated that less than $1 \%$ of all readings were related to environmental politics..$^{10}$ In short, graduate students are not observing much in the way of successful environmental research.

\section{IR AND THE ENVIRONMENT: THREE POTENTIAL RESEARCH AGENDAS}

The marginalization of GEP within IR represents an important missed opportunity for the discipline. We propose three lines of research to correct this imbalance that can broaden the scope of IR by using extant theories to explain outcomes in a different area of world politics: the environmental arena. Conversely, it can strengthen the subfield by encouraging environmental scholars to consider the applicability of their work to the broader discipline. We recognize that there are empirical challenges specific to the study of GEP. Some outcomes (e.g., global temperature change) are predicted but have only recently begun to occur. In other cases (e.g., the extent of biodiversity loss or fishery populations), there are limited data, often surrounded by a great degree of uncertainty. These challenges may require new methodological approaches, particularly those that provide traction on prospective trends (e.g., natural and field experiments that simulate future conditions). However, these difficulties do not appear to be any more difficult than challenges in other subfields-for example, studying rare events such as interstate war or long-term normative shifts in the field of human rights.

\section{New Frontiers for Empirical Investigation}

The first research area follows directly from the empirical findings described previously. Several global environmental topics raise key political issues, but top IR journals tend to publish more on climate change-specifically, climate mitigation and the implications of climate change for security-than on any other subject. Although climate change has become enormously salient, numerous environmental problems exist-even at the level of planetary, systemic threats to human well-being-all of which involve complicated political issues that should be of concern to IR scholars. Ecologists have identified no fewer than nine "planetary boundaries" - that is, threats to key natural "life-support systems" that humans and other forms of life depend on for survival (Rockstrom et al. 2009). Climate change is only one threat; the others are biodiversity loss, biogeochemical processes (i.e., nitrogen and phosphorous), ocean acidification, land-use changes, freshwater depletion, ozone depletion, atmospheric aerosols, and chemical pollution. Whereas the global governance of the ozone has received significant attention in the IR literature-along with specific elements of other boundaries (e.g., cross-border air pollution, forest governance, and transboundary river systems)-large swaths of the governing institutions for environmental problems remain terra incognita for IR theorists. For example, fish provide approximately one fifth of the world's protein intake; some estimates suggest that all commercial fisheries will collapse by 2050 (Food and Agriculture Organization 2014). A range of international treaties and institutions governs fisheries with numerous contentious disputes. Yet, only two of the 5,306 articles in the TRIP database study fisheries. ${ }^{11}$

Second, there are profound theoretical questions surrounding the capabilities of the current world order to address planetary threats with high degrees of uncertainty. The planetary boundaries described above interact in complex ways, many of which are not yet well understood. Solving one threat provides no guarantee that others will improve as well. Instead, it is likely that a mix of positive and negative externalities can be expected. This complexity of environmental systems raises new challenges for our political systems. Much of the IR work in GEP to date focuses on mechanisms that promote international cooperation, most of it resulting from early work on interdependence and regime design. However, it has been observed that traditional multilateral approaches-even if successful in areas such as ozone depletion and transboundary air pollutionstruggle to address more systemic issues including biodiversity loss, deforestation, and climate (Hale, Held, and Young 2013). More recent work has focused instead on various dimensions of institutional complexity (Abbott, Green, and Keohane 2016; Jinnah 2014; Johnson and Urpelainen 2012; Orsini 2013; Zelli 2011) or has made more radical critiques about the relationship between capitalism and sustainability (Klein 2015). Thus, the reality of politics in the Anthropocene may lead political scientists to more fundamental questions about political order, the nature of contemporary capitalism, and state survival than are commonly tackled in the field.

Third, as we continue to alter the world in fundamental ways, new environmental problems of political concern are likely to arise. For example, scientists are already exploring the possibility of intentionally altering the Earth's climate with technologies to remove carbon from the atmosphere (i.e., by dumping masses of 
iron filings into the ocean to fertilize algae) and shielding the planet from incoming solar radiation (i.e., by spraying tiny particles of sulphur into the upper atmosphere). Although these interventions are not yet well understood, many fear that they have significant potential to create sharp losses and gains (e.g., protecting one area of the planet from heat waves while plunging another area into drought), thereby fomenting international conflict. For this reason, there is a growing literature on potential international political consequences and global governance of geoengineering (Lloyd and Oppenheimer 2014; Parson and Ernst 2013; Urpelainen 2012). However, it is striking that most scholars working in this field are natural scientists and lawyers, not IR specialists. it provided significant material for the study of institutionalization and legalization, bargaining, interaction of domestic and international politics, and other topics of general interest to IR scholars throughout the discipline. We suggest that the relative complexity and plurality of environmental actors and institutions in world politics provides a similarly rich vein of theoretical ore for scholars to mine, and one that remains largely unexploited.

\section{Knowledge, Uncertainty, and Risk}

Finally, GEP highlights the role of uncertainty and knowledge in shaping political outcomes. Scientific knowledge is a key factor in international cooperation. Although the precautionary principle states that uncertainty should not be an obstacle to action,

\section{Thus, the reality of politics in the Anthropocene may lead political scientists to more fundamental questions about political order, the nature of contemporary capitalism, and state survival than are commonly tackled in the field.}

Beyond this fertile terrain for empirical exploration, the study of GEP raises a number of theoretical questions of broader significance to the discipline, to which we now turn.

\section{Pluralism and Complexity}

GEP has sharpened the discipline's attention to the growing plurality and complexity of actors, institutions, and processes through which world politics occurs. To be sure, such trends can be seen across nearly every issue area (Hale and Held 2011). We suggest that these trends are most pronounced in the realm of environmental politics. Indeed, from the time that countries first began to cooperate about environmental issues (around the turn of the last century), governance arrangements tend to resemble the multiactor, informal networks that are now commonplace (Boardman 1981). More recently, environmental politics has drawn the discipline's attention to the role of pluralism and institutional complexity in world politics. The environmental realm has been perhaps the largest source of empirical studies of transitional governance institutions, especially public- private partnerships, voluntary regulations and certification schemes, transgovernmental networks, and private authority. By assessing these developments, scholars of environmental politics help us to understand the effects of an increasingly dense and overlapping set of governance institutions and processes, highlighting questions of regime complexity (Keohane and Victor 2011; Raustiala and Victor 2004), fragmentation (Biermann et al. 2009; Zelli 2011), institutional ecosystems (Abbott et al. 2016), and polycentricity (Ostrom 2010).

The high degree of plurality and complexity of actors and governance institutions in the environmental realm makes it an ideal laboratory for IR scholars to study these trends, which, as mentioned previously, can be increasingly observed in almost any field of world politics. In this way, environmental politics in the twenty-first century provides the same type of theoretical potential that the study of trade politics provided in the late twentieth century. Because global governance of trade is characterized by well-developed intergovernmental organizations and international law (relative to other areas of world politics), in practice, it often is politicized, as in the United States regarding climate change. With some exceptions, we know relatively little about how scientific knowledge affects cooperation. As new issues such as genetically modified organisms and geoengineering emerge, understanding the conditions under which scientific knowledge can help (or hinder) cooperation will be increasingly important.

Much of this scientific knowledge comes from scientists-an important set of actors in environmental governance. The recognition of epistemic communities as a real and salient political force was made possible by the investigation of expert knowledge in environmental politics (Haas 1992). How are these networks of actors formed? Who is included or excluded and why? Similarly, scientists played an important role in the ozone discourse (Litfin 1994) and, of course, climate change (Oreskes 2007). Although environmental issues are particularly ready for scientific input, they are similar to other technical issues in world politics that require significant expertise to navigate. As we move ever deeper into the "risk society"-in which modernity creates more environmental risks that require systematic management-the role of experts becomes increasingly important and political (Beck 1992). Although there has been some work on the role of scientific assessments (Mitchell et al. 2006), we must conduct more comparative work about the conditions under which scientists affect policy-making processes.

\section{CONCLUSION: BRINGING ENVIRONMENTAL POLITICS FULLY INTO THE DISCIPLINE}

This article identifies a doubly puzzling imbalance in our discipline. IR scholars identify environmental issues as among the most important the world faces, and our discipline possesses unique theoretical tools to address these challenges. Yet, few IR scholars study the topic, and even fewer articles on the subject are published in top IR journals.

At the same time, policy makers look to the natural sciences, economics, law, and elsewhere for answers to questions that should be the bailiwick of political science. In recognizing this analytic and theoretical deficit, there are increasing calls for natural scientists 
to take seriously the social and political sciences (Victor 2015). However, as the cited data show, it is incumbent on IR scholars to reach out as well.

Bringing environmental politics fully into the discipline would provide three benefits. First, from a scientific perspective, greater attention from IR scholars to environmental issues would enrich the discipline by testing theories developed primarily in the security and economic realms in a different domain of politics. Environmental politics promises to bring a steady stream of raw material-issues, puzzles, data, and cases-into the scientific process. Without such ongoing engagement to test and build on the discipline's core knowledge, stagnation results.

Second, bringing GEP into the IR mainstream also would strengthen the subfield. Scholars of GEP must ensure that their concepts and theories migrate to other areas of politics. It may be that some political phenomena are unique or at least substantially different in the environmental realm; however, our starting assumption is that such cases are rare: environmental politics are politics. If environmental scholarship remains published primarily in a relatively isolated subfield, then environmental scholars are at risk to miss theoretical, methodological, and empirical advances from other realms.

Third, what is good for science is also good for policy. Policy makers need political insights to develop effective solutions to global environmental challenges, as argued herein. Without attention to distribution and power, institutional design, the role of norms and ideas, and other political dynamics, global environmental governance is unlikely to succeed. Participating more forcefully in this debate will delineate the unique contributions of political science vis-à-vis economics, law, and other disciplines. It also means that we will engage in debates regarding values; we believe there should be space in IR for such discussions, provided that they are supported by sound social science.

IR scholars have every reason to shoulder the "responsibility" and seize the "opportunity" of fully engaging GEP (Keohane $2015,25)$. However, as political scientists, our starting assumption is that exhortations to accomplish more in this area alone will not rectify the situation without a commensurate shift in incentives. To be blunt, until scholars-particularly younger scholars-see opportunities for career advancement in environmental politics, we are unlikely to observe substantial change. It is crucial, therefore, for journal editors, dissertation advisers, hiring committees, graduate-course conveners, funders, and other gatekeepers in the field to increase the priority they place on environmental themes. As with environmental problems, solutions to the political-science deficit in global environmental problems are possible, but they require concerted action.

\section{NOTES}

1. Available at https://trip.wm.edu/charts/\#/bargraph/41/6717. The TRIP Project is based at the College of William \& Mary's Institute for the Theory and Practice of International Relations. It conducts the most comprehensive and regular surveys of the discipline.

2. TRIP did not survey scholars based in other countries on this question.

3. Available at http://iea.uoregon.edu/page.php?query=static\&file=definitions.htm.

4. We are indebted to Mike Tierney, Sue Peterson, and Dan Maliniak for allowing us to use their data. Further information on these samples and their respective methodologies is available at www.wm.edu/offices/itpir/trip/index.php.

5. Research area was self-identified by the survey respondents.

6. The estimates of primary GEP scholarship were based on the 1,576 respondents who provided valid responses to the question about their main research area secondary GEP prevalence estimates were based on the 1,444 respondents who provided valid information on their secondary research areas. This is why the overall GEP prevalence estimate (i.e., primary + secondary GEP scholars) is not equal to the sum of the primary and secondary estimated rates.

7. These are American Journal of Political Science, Journal of Politics, World Politics, International Studies Quarterly, Journal of Conflict Resolution, American Political Science Review, International Security, International Organization, British Journa of Political Science, European Journal of Political Science, Security Studies, and Journal of Peace Research.

8. According to the TRIP codebook, "issue area" is described as the "subfields within IR" and the substantive focus is the "major topic addressed." The substantive focus was coded according to the following procedure: "The rule of thumb/question that coders were supposed to ask themselves was 'If you were a scholar interested in trade (for example), is this an article you would like to return to in a search for articles on trade?" More information on the codebook and replication data is available at https://trip.wm.edu/home/ index.php/data/replication-data.

9. The two journals are Comparative Politics and Comparative Political Studies.

10. This calculation is based on correspondence with Jeff Colgan. Although the syllabi were not coded by issue area, he noted that only 13 of the 2,069 readings in the dataset corresponded to the search terms "environment, pollution, ozone, climate, and green."

11. For excellent monographs on fisheries, see Webster (2008) and Barkin and DeSombre (2013)

\section{REFERENCES}

Abbott, Kenneth W., Jessica F. Green, and Robert O. Keohane. 2016. "Organizational Ecology and Institutional Change in Global Governance." International Organization $70(2): 1-31$.

Aldy, Joseph E. and Robert N. Stavins. 2012. "The Promise and Problems of Pricing Carbon Theory and Experience." Journal of Environment \& Development 21 (2): 152-8o. doi:10.1177/1070496512442508.

Barkin, J. Samuel and Elizabeth R. DeSombre. 2013. Saving Global Fisheries: Reducing Fishing Capacity to Promote Sustainability. Cambridge: MIT Press.

Beck, Ulrich. 1992. Risk Society: Towards a New Modernity. London: Sage Publications.

Biermann, Frank, Philipp Pattberg, Harro van Asselt, and Fariborz Zelli. 2009 "The Fragmentation of Global Governance Architectures: A Framework for Analysis." Global Environmental Politics 9 (4): 14-40.

Boardman, Robert. 1981. International Organizations and the Conservation of Nature. Bloomington: Indiana University Press.

Bodansky, Daniel. 2010. The Art and Craft of International Environmental Law. Cambridge, MA: Harvard University Press.

Bulkeley, Harriet, Liliana Andonova, Michele M. Betsill, Daniel Compagnon, Thomas Hale, Matthew J. Hoffmann, et al. 2014. Transnational Climate Change Governance. Cambridge: Cambridge University Press.

Cao, Xun, Helen V. Milner, Aseem Prakash, and Hugh Ward. 2013 "Research Frontiers in Comparative and International Environmental Politics: An Introduction." Comparative Political Studies (December). doi:10.1177/0010414013509567.

Colgan, Jeff D. 2016. "Where Is International Relations Going? Evidence from Graduate Training." International Studies Quarterly: First View. Available at http://dx.doi.org/10.1093/isq/sqv017.

FAO, The State of World Fisheries and Aquaculture: Opportunities and Challenges (FAO, 2014), available at: http://www.fao.org/3/a-i3720e.pdf.

Green, Jessica F. 2014. Rethinking Private Authority: Agents and Entrepreneurs in Global Environmental Governance. Princeton, NJ: Princeton University Press.

Haas, Peter M. 1992. "Introduction: Epistemic Communities and International Policy Coordination." International Organization 46 (1): 1-35.

Haas, Peter, Robert O. Keohane, and Marc A. Levy (eds.). 1993. Institutions for the Earth: Sources of Effective International Environmental Protection. Cambridge, MA: MIT Press.

Hadden, Jennifer. 2015. Networks in Contention: The Divisive Politics of Climate Change. Cambridge: Cambridge University Press.

Hale, Thomas N. and David Held. 2011. Handbook of Transnational Governance: Institutions and Innovation. Cambridge: Polity.

Hale, Thomas N., David Held, and Kevin Young. 2013. Gridlock: Why Global Cooperation Is Failing When We Need It Most. Boston: Polity.

Hicks, Robert L., B. Parks, T. Roberts, and MJ Tierney. 2008. Greening Aid? Understanding the Environmental Impact of Development Assistance. Oxford: Oxford University Press.

Javeline, Debra. 2014. The Most Important Topic Political Scientists Are Not Studying: Adapting to Climate Change. Perspectives on Politics 12 (02): $420-434$. 
Jinnah, Sikina. 2014. Post-Treaty Politics: Secretariat Influence in Global Environmental Governance. Cambridge, MA: MIT Press.

Johnson, Tana and Johannes Urpelainen. 2012. "A Strategic Theory of Regime Integration and Separation." International Organization 64 (2): 645-77.

Keohane, Nathaniel, Annie Petsonk, and Alex Hanafi. 2015. "Toward a Club of Carbon Markets." Climatic Change (October) 1-15. doi:10.1007/s10584-015-1506-z.

Keohane, Robert O. 2015. The Global Politics of Climate Change: Challenge for Political Science. PS: Political Science and Politics. 48 (01): 19-26.

Keohane, Robert O. and David G. Victor. 2011. "The Regime Complex for Climate Change." Perspectives on Politics 9 (1): 7-23.

Klein, Naomi. 2015. This Changes Everything: Capitalism vs. The Climate. New York: Simon \& Schuster.

Litfin, Karen. 1994. Ozone Discourses: Science and Politics in Global Environmental Cooperation. New Directions in World Politics. New York: Columbia University Press.

Lloyd, Ian D. and Michael Oppenheimer. 2014. "On the Design of an International Governance Framework for Geoengineering." Global Environmental Politics, 14 (2): 45-63.

Mitchell, Ronald Bruce. 2016. International Environmental Agreements (IEA) Database Project. University of Oregon. Available at: http://iea.uoregon.edu. Accessed September 1, 2016.

Mitchell, Ronald Bruce, William Clark, David Cash, and Nancy Dickson (eds.). 20o6. Global Environmental Assessments: Information and Influence. Cambridge, MA: MIT Press.

Oreskes, Naomi. 2007. "The Scientific Consensus on Climate Change: How do we know we're not wrong?" In Jospeh DiMento and Pamela Doughman, eds. Climate Change: What it means for us, our children and our grandchildren. Cambridge: MIT Press.
Orsini, Amandine. 2013. "Multi-Forum Non-State Actors: Navigating the Regime Complexes for Forestry and Genetic Resources." Global Environmental Politics $13(3): 34-55$.

Ostrom, Elinor. 2010. "Polycentric Systems for Coping with Collective Action and Global Environmental Change." Global Environmental Change, 2oth Anniversary Special Issue, 20 (4): 550-57.

Parson, Edward A. and Lia N. Ernst. 2013. "International Governance of Climate Engineering." Theoretical Inquiries in Law 14: 307-337.

Phelps, Jacob, Edward L. Webb, and Arun Agrawal. 2010. "Does REDD+ Threaten to Recentralize Forest Governance?” Science 328 (5976): 312-13.

Raustiala, Kal and David G. Victor. 2004. "The Regime Complex for Plant Genetic Resources." International Organization 58 (2): 277-309.

Rockstrom, Johan, Will Steffen, Kevin Noone, Asa Persson, F. Stuart Chapin, Eric F. Lambin, et al. 2009. "A Safe Operating Space for Humanity." Nature $461(7263): 472-5$.

Sands, Philippe and Jacqueline Peel. 2012. Principles of International Environmental Law. Cambridge: Cambridge University Press.

Steinberg, P. F. and S. D. VanDeveer. 2012. Comparative Environmental Politics: Theory, Practice, and Prospects (Cambridge, MIT Press).

Urpelainen, Johannes. 2012. "Geoengineering and Global Warming: A Strategic Perspective." International Environmental Agreements: Politics, Law and Economics $12(4): 375^{-89}$.

Victor, David G. 2015. "Climate Change: Embed the Social Sciences in Climate Policy." Nature 520 (7545): 27-9.

Webster, D. G. 2008. Adaptive Governance: The Dynamics of Atlantic Fisheries Management. Cambridge, MA: MIT Press.

Zelli, Fariborz. 2011. "The Fragmentation of the Global Climate Architecture." Wiley Interdisciplinary Reviews: Climate Change 2 (2): 255-70. 